Article

\title{
Cognitive Impairments and Self-Reported Sleep in Early-Stage Parkinson's Disease with Versus without Probable REM Sleep Behavior Disorder
}

\author{
Jonathan Trout ${ }^{1}$, Taylor Christiansen ${ }^{1}$, M. Brooks Bulkley ${ }^{1}$, Jared J. Tanner ${ }^{2}$, \\ Christopher N. Sozda ${ }^{2}$, Dawn Bowers ${ }^{2}$ and Daniel B. Kay ${ }^{1, *}$ \\ 1 Department of Psychology, Brigham Young University, Provo, UT 84602, USA; \\ jonathan.trout2015@gmail.com (J.T.); taylor7832@gmail.com (T.C.); brooksbulkley@gmail.com (M.B.B.) \\ 2 Department of Clinical and Health Psychology, University of Florida, Gainesville, FL 32611, USA; \\ jjtanner@gmail.com (J.J.T.); christopher.sozda@va.gov (C.N.S.); dawnbowers@phhp.ufl.edu (D.B.) \\ * Correspondence: daniel_kay@byu.edu; Tel.: +1-801-422-7949
}

Received: 16 November 2019; Accepted: 19 December 2019; Published: 21 December 2019

\begin{abstract}
Parkinson's disease (PD) is associated with cognitive and sleep impairments. The presence of rapid eye movement (REM) sleep behavior disorder (RBD) symptoms may represent a worse disease prognosis for PD individuals. We investigated cognitive functioning and self-reported sleep in early-stage PD individuals with $(n=19)$ or without $(n=31)$ probable RBD. Probable RBD was defined as $>5$ on the REM Sleep Behavior Disorder Screening Questionnaire. Inhibition, visuospatial cognitive abilities, working memory, sustained visual attention, verbal fluency, and episodic memory were assessed. Sleep impairments were assessed using the Pittsburgh Sleep Quality Index, Insomnia Severity Index, Epworth Sleepiness Scale, and Patient-Reported Outcomes Measurement Information System questionnaires. Chi-squared, Mann-Whitney $U$, and independent sample $t$-tests were employed to assess group differences. Participants with PD and probable RBD performed significantly worse on word reading and switching verbal fluency tasks than PD participants without probable RBD $(p<0.05)$. No significant differences were found in mood, PD severity, or sleep measures between PD individuals with or without probable RBD. Cognitive tasks that involve verbal or switching components may be most impaired in PD individuals with probable RBD. Larger samples are needed to determine whether other cognitive domains and sleep features are significantly associated with RBD in PD.
\end{abstract}

Keywords: REM sleep behavior disorder; Parkinson's disease; sleep quality; executive control; cognition; verbal fluency

\section{Introduction}

Parkinson's disease (PD) is a common neurodegenerative movement disorder characterized by resting tremor, rigidity, bradykinesia, and postural instability. As a complex, multifaceted disorder, PD is associated with cognitive impairment [1-7] and sleep problems [8-12]. Rapid eye movement (REM) sleep behavior disorder (RBD) affects up to $37-47 \%$ of PD patients $[7,13]$ and is one of the most common and distressing sleep disorders associated with PD. The loss of muscle atonia during REM sleep in RBD and "acting out" dreams can lead to injury for PD individuals and their bed partners [14]. The presence of RBD in PD may represent a more severe disease prognosis associated with accelerated cognitive decline and poorer sleep [15-17].

Several studies have investigated the impact of RBD on cognitive functioning in PD [18-22]. While differing in the domains examined and the measures used, these studies identified that RBD 
in PD is most consistently associated with poorer performance on executive functioning, attention, verbal learning and memory, and visuospatial processing tasks [18-20,23]. One study found that RBD in PD was not associated with poorer performance on nonverbal learning and memory tasks [18], suggesting a potential link to unique verbal deficiencies in PD patients with RBD. Understanding the connection between specific cognitive impairments associated with RBD in PD patients may elucidate their pathophysiology and lay the groundwork for effective treatments of these impairments.

The impact of RBD on sleep quality has been a common question in the literature. Some studies have investigated the impact of RBD on polysomnographic sleep measures and found that RBD was associated with more night-time awakenings and decreased sleep duration, particularly in REM sleep $[14,21,24]$. However, other studies found that RBD was not associated with some sleep measures, such as sleep latency and sleep efficiency [14,25]. The effect of RBD on self-reported sleep measures in PD patients is limited primarily to measures of daytime sleepiness, insomnia severity, and a PD sleep scale [18-20,24,26]. Most studies found no association between daytime sleepiness or insomnia severity with RBD in PD patients [18-20,26], but some found an association with daytime sleepiness or the PD sleep scale $[24,26]$. When a study investigated the relationship between idiopathic RBD (iRBD) and subjective sleep measures, iRBD participants reported greater insomnia severity and sleep disturbance, suggesting RBD as a potential contributor to sleep problems [27]. Investigating subjective sleep across a wider variety of sleep measures in PD patients with RBD may elucidate specific self-reported sleep problems associated with RBD and could shed light on the mixed findings in the literature.

The purpose of this analysis was to investigate whether individuals with probable RBD and early-stage PD $(n=19)$ exhibit greater cognitive impairment than PD individuals without RBD symptoms $(n=31)$. We hypothesized that the combination of early-stage PD and probable RBD would result in greater cognitive impairment. We also explored whether individuals with PD who had probable RBD had poorer self-reported sleep across a wide variety of sleep features compared to PD individuals without probable RBD.

\section{Materials and Methods}

\subsection{Participants}

This study is a secondary analysis of data collected to investigate the impact of PD on sleep, cognition, and mood. Participants with PD were categorized as having probable RBD based on a REM Sleep Behavior Disorder Screening Questionnaire (RBDSQ) score greater than 5 [28]. Demographic and sleep features of this sample have been reported previously [29]. Most participants were older adults $(M d n=66.5)$, white $(76 \%)$, and male $(76 \%)$. The groups were similar in demographic characteristics, except for age; probable RBD group participants were significantly older than those without probable RBD.

Participants were recruited from the University of Florida (UF) Center for Movement Disorders and Neurorestoration (CMDN). The Unified Parkinson Disease Rating Scale (UPDRS) [30] was used to clinically diagnose idiopathic PD. Participants presented with early-to-middle stage PD based on a Hoehn-Yahr staging score $(M=1.8, S D=1.1)$ [31]. The disease information for PD participants was obtained from a clinical research database maintained by the UF CMDN. This study was conducted with the evaluation and approval of the UF Institutional Review Board (IRB-01\# 117-2011). Exclusion criteria for the study were: (1) the inability to give informed consent, (2) lower than an 8th grade education, (3) evidence of significant neurological problems other than PD (tumors, epilepsy, etc.), (4) significant medical problems other than PD such as myocardial infarction ( $<6$ months), congestive heart failure (functional stage $>3$ ), etc., (5) a severe psychiatric disease including a prior history of substance abuse disorder, psychosis, mania, obsessive compulsive disorder, attention deficit disorder, and post-traumatic stress disorder or a current severe major depressive disorder determined by a score $>19$ on the Patient Health Questionnaire-9 [32], (6) a reduced mental status based on scores $<25$ on the Mini-Mental State Exam [33], (7) an inability to read and comprehend English, (8) a history of 
neurosurgery, (9) diagnosis, treatment, or bed partner reports suggestive of obstructive sleep apnea, restless leg syndrome, or periodic limb movement disorder, and (10) a lack of a bed partner able to document the absence of these sleep disorder symptoms.

\subsection{Measures}

\subsubsection{Overview}

Participants completed a screening survey, a semi-structured clinical sleep interview, several sleep- and mood-related questionnaires, and a selected battery of neuropsychological measures in private testing rooms at UF or in the participants' home. Anxiety and mood were assessed using the State-Trait Anxiety Inventory [34] and the Patient Health Questionnaire-9 [32], respectively. Severity of PD was measured using the Unified Parkinson's Disease Rating Scale and PD duration, which was measured in months. Neuropsychological testing occurred while PD individuals were medicated. This study compared groups (PD with vs. without probable RBD) across several demographic, mood, PD severity, cognitive, and sleep variables.

\subsubsection{Cognition Measures}

The Color-Word Interference Test of the Delis-Kaplan Executive Functioning System (D-KEFS) was employed to evaluate cognitive response inhibition [35]. The scores were converted to scaled-score equivalents according to age norms using the D-KEFS manual. Lower scores on the inhibition task indicated lower cognitive inhibition. The Judgment of Line Orientation (JOLO) test was used to evaluate visuospatial processing [36]. Scores were converted to scaled scores according to age norms [37]. Higher scores indicated better visuospatial performance. Working memory was assessed using the average accuracy and response time on the 2- and 3-back conditions of a computerized n-back task [38]. Higher accuracy scores and lower response times indicated better working memory. A continuous performance task (CPT) was used to evaluate sustained visual attention [39]. Lower response times and higher accuracy scores indicated better sustained attention. Cognitive-shifting was evaluated using the category switching condition of the D-KEFS Verbal Fluency test. Higher scores on the switching task were conceptualized as better cognitive-shifting. A story memory test, modeled after the Logical Memory subtest of the Wechsler Memory Scale (WMS III, IV), was employed to assess episodic memory [40]. Immediate and 30-minute-delayed responses were recorded after two stories were read to the participants. Due to an experimenter error, one participant's performance was not recorded. Higher scores on this test indicated better episodic memory.

\subsubsection{Sleep Measures}

The total score on the Pittsburgh Sleep Quality Index (PSQI) was used to assess subjective sleep quality [41]. Item 4 of the PSQI was used to assess average subjective total sleep time normally obtained each night over the previous month [42]. Higher total sleep time and global PSQI indicated better sleep quality. The Insomnia Severity Index (ISI) was used to assess the sleep quality and insomnia severity over the previous 2 weeks [43]. Higher ISI scores indicated higher insomnia severity and lower sleep quality. The Epworth Sleepiness Scale (ESS) was employed to provide an index of the severity of daytime sleepiness [44]. Higher ESS scores indicated higher daytime sleepiness. The Patient-Reported Outcomes Measurement Information System Sleep Disturbance (PROMIS-SD) and the Sleep-Related Impairment (PROMIS-SRI) questionnaires were used to assess sleep disturbance and sleep-related impairment, respectively [45]. Higher scores on these questionnaires represented greater sleep disturbance and sleep-related impairment, respectively.

\subsection{Analyses}

All variables were assessed for normality within each group using the Shapiro-Wilk test and visual inspection of histogram distributions. Statistical significance was set at $p<0.05$. Chi-squared 
test, Mann-Whitney $U$ test, or independent sample $t$-tests were used to compare demographic, mood, PD severity, cognition, and sleep measures in PD participants with probable to PD participants without probable RBD. IBM SPSS 26 statistical software was used to analyze these data. Effect sizes were calculated using $\phi$ for measures compared using $2 \times 2$ contingency table Chi-squared tests, Cramer's $V$ for measures compared using non- $2 \times 2$ contingency Chi-squared tests, Spearman's Rho $\left(r_{s}\right)$ for measures compared using Mann-Whitney $U$ tests, and Cohen's $d$ for measures compared using independent sample $t$-tests. Pirate plots created in $\mathrm{R}$ were used to visualize group differences in variables with moderate-to-strong effect sizes $(\phi>0.3$, Cramer's $V>0.13$ for $d f=5, r>0.3$, and Cohen's $d>0.5)$.

\section{Results}

\subsection{Probable RBD and Cognition Analyses}

Participants with probable RBD had poorer performance on verbal fluency category switching and word reading tasks than participants without probable RBD (Table 1). There were no significant group differences between the PD with probable RBD and the PD without probable RBD groups on tasks of cognitive inhibition, visuospatial processing, working memory, sustained attention, or episodic memory (Table 1). The pirate plots and effect sizes suggest that PD participants with probable RBD tended to have a worse performance on category switching verbal fluency (Figure 1) and word reading tasks (Figure 2).

\subsection{Probable RBD and Demographic, Sleep, Mood, and PD Severity Analyses}

Age was the only demographic variable that significantly differed between the two groups $(p>0.05 ;$ Table 1$)$. No significant group differences were found in the sleep, mood, or PD severity measures between the PD without probable RBD and the PD with probable RBD groups (Table 1). 
Table 1. Demographic, mood, Parkinson's disease (PD) severity, cognition, and sleep measures in PD individuals with or without probable rapid eye movement sleep behavior disorder (pRBD).

\begin{tabular}{|c|c|c|c|c|c|c|}
\hline & $\begin{array}{l}\text { PD with pRBD } \\
\quad(n=19)\end{array}$ & $\begin{array}{l}\text { PD without pRBD } \\
\qquad(n=31)\end{array}$ & $\chi^{2} / Z / t$ & $d f$ & $p$-Value & $\begin{array}{l}\text { Effect Size } \\
\left(\phi / V / r_{s} / d\right)\end{array}$ \\
\hline \multicolumn{7}{|l|}{ Demographic, Mood, and PD Measures } \\
\hline Age, $y$ & $70.1(7.4)$ & $65.7(6.6)$ & -2.16 & 48 & $0.036 *$ & $d=-0.62$ \\
\hline Male sex, $n$ & 16 & 22 & 1.13 & 1 & 0.760 & $\phi=0.15$ \\
\hline Education, $\mathrm{y}$ & $16[13,20]$ & $16[12,18]$ & -0.84 & & 0.400 & $r_{S}=-0.12$ \\
\hline White, $n$ & 16 & 22 & 0.13 & 1 & 0.721 & $\phi=0.05$ \\
\hline Married, $n$ & 15 & 28 & 5.71 & 5 & 0.335 & $V=0.15$ \\
\hline State-Trait Anxiety Inventory, State & $25[20,41]$ & $35[27,43]$ & 1.69 & - & 0.091 & $r_{S}=0.24$ \\
\hline Patient Health Questionnaire-9 & $5[3,8]$ & $6[2,10]$ & 0.20 & - & 0.841 & $r_{S}=0.03$ \\
\hline Modified Hoehn-Yahr Scale ${ }^{+}$ & $2[2,2]$ & $2[2,2]$ & 0.92 & - & 0.358 & $r_{s}=0.13$ \\
\hline PD duration, mos $\ddagger$ & $84[36,120]$ & $96[66,135]$ & 0.73 & - & 0.330 & $r_{S}=0.12$ \\
\hline \multicolumn{7}{|l|}{ Cognition Measures } \\
\hline \multicolumn{7}{|l|}{ D-KEFS Color-Word Interference Test } \\
\hline Color naming, ss & $8.7(2.5)$ & $9.7(2.4)$ & 1.42 & 48 & 0.162 & $d=0.41$ \\
\hline Word reading, ss & $8.7(2.7)$ & $10.3(2.6)$ & 2.06 & 48 & 0.044 * & $d=0.60 \S$ \\
\hline Inhibition, ss & $9.2(3.1)$ & $10.0(3.7)$ & 0.80 & 48 & 0.425 & $d=0.23$ \\
\hline Switching, ss $\ddagger$ & $9.4(3.5)$ & $10.8(2.4)$ & 1.65 & 46 & 0.106 & $d=0.48$ \\
\hline Visuospatial processing, JOLO, ss & $12.2(2.8)$ & $12.2(2.4)$ & 0.01 & 48 & 0.996 & $d=0.00$ \\
\hline \multicolumn{7}{|l|}{ Working Memory, 2- \& 3-back } \\
\hline Average accuracy $\dagger \ddagger$ & $0.8[0.8,0.9]$ & $0.9[0.8,0.9]$ & -0.71 & & 0.480 & $r_{s}=0.10$ \\
\hline Average RT, ms ${ }^{\dagger \ddagger}$ & $876[781,875]$ & $902[768,902]$ & -0.48 & & 0.633 & $r_{s}=0.07$ \\
\hline \multicolumn{7}{|l|}{ Sustained Attention, CPT } \\
\hline Total accuracy ${ }^{\dagger}$ & $0.9[0.6,1.0]$ & $0.9[0.8,1.0]$ & -0.51 & - & 0.608 & $r_{s}=0.04$ \\
\hline Total RT, $\mathrm{ms}^{+}$ & $399[374,476]$ & $394.0[357,455]$ & -0.26 & - & 0.797 & $r_{S}=-0.07$ \\
\hline \multicolumn{7}{|l|}{ D-KEFS Verbal Fluency Test } \\
\hline Letter, ss ${ }^{\dagger}$ & $10.4(3.4)$ & $11.2(3.7)$ & 0.70 & 47 & 0.485 & $d=0.20$ \\
\hline Category, ss ${ }^{+}$ & $9.6(2.3)$ & $11.0(3.3)$ & 1.66 & 47 & 0.104 & $d=0.48$ \\
\hline Switching, ss ${ }^{+}$ & $7.8(4.1)$ & $10.3(3.2)$ & 2.38 & 47 & $0.021 *$ & $d=0.69 \S$ \\
\hline \multicolumn{7}{|l|}{ Episodic memory, stories } \\
\hline Immediate recall $^{+}$ & $20.0(6.1)$ & $21.0(4.8)$ & 0.59 & 47 & 0.561 & $d=0.17$ \\
\hline Delayed recall ${ }^{\dagger}$ & $17.0(5.4)$ & $17.0(4.5)$ & 0.19 & 47 & 0.854 & $d=0.06$ \\
\hline
\end{tabular}


Table 1. Cont.

\begin{tabular}{|c|c|c|c|c|c|c|}
\hline & $\begin{array}{c}\text { PD with pRBD } \\
(n=19)\end{array}$ & $\begin{array}{c}\text { PD without pRBD } \\
(n=31)\end{array}$ & $x^{2} / \mathrm{Z} / t$ & $d f$ & $p$-Value & $\begin{array}{l}\text { Effect Size } \\
\left(\phi / V / r_{s} / d\right)\end{array}$ \\
\hline \multicolumn{7}{|l|}{ Sleep Measures } \\
\hline Pittsburgh Sleep Quality Index total score & $6.9(5.2)$ & $7.1(3.2)$ & 0.15 & 48 & 0.878 & $d=0.04$ \\
\hline Total sleep time, $\min$ & $396(105)$ & $401(65)$ & 0.23 & 48 & 0.816 & $d=0.24$ \\
\hline Insomnia Severity Index total score & $8[3,15]$ & $6[3,12]$ & -0.84 & - & 0.399 & $r_{s}=-0.12$ \\
\hline Epworth Sleepiness Scale total score & $10[7,16]$ & $8[4,9]$ & -1.80 & - & 0.073 & $r_{S}=-0.26$ \\
\hline Sleep disturbance, PROMIS-SD ${ }^{\dagger}$ & $53[41,77]$ & $52[45,59]$ & -0.51 & - & 0.608 & $r_{S}=-0.07$ \\
\hline Sleep-related impairment, PROMIS-SRI ${ }^{\dagger}$ & $31[27,49]$ & $34[26,38]$ & -0.81 & - & 0.417 & $r_{s}=0.12$ \\
\hline
\end{tabular}

Note. Data that were not normally distributed are reported as $M d n[I Q R]$. Percentiles were determined using weighted averages. Normally distributed data are reported as $M(S D) .{ }^{+}$ pRBD groups differed significantly from each other at the $p<0.05$ level. $\Phi:$ Mean Square Contingency Coefficient. $V:$ Cramer's $V$. $r_{s}$ : Spearman's Rho. $d$ : Cohen’s $d$. $\S^{\circledR}$ indicates a medium effect size. ss: scaled score equivalent based on age norms. D-KEFS: Delis-Kaplan Executive Functioning System. JOLO: Judgment of Line Orientation. RT: response time. CPT: Continuous Performance Task. PROMIS-SD: Patient-Reported Outcomes Measurement Information System-Sleep Disturbance. SRI: Sleep-Related Impairment. 


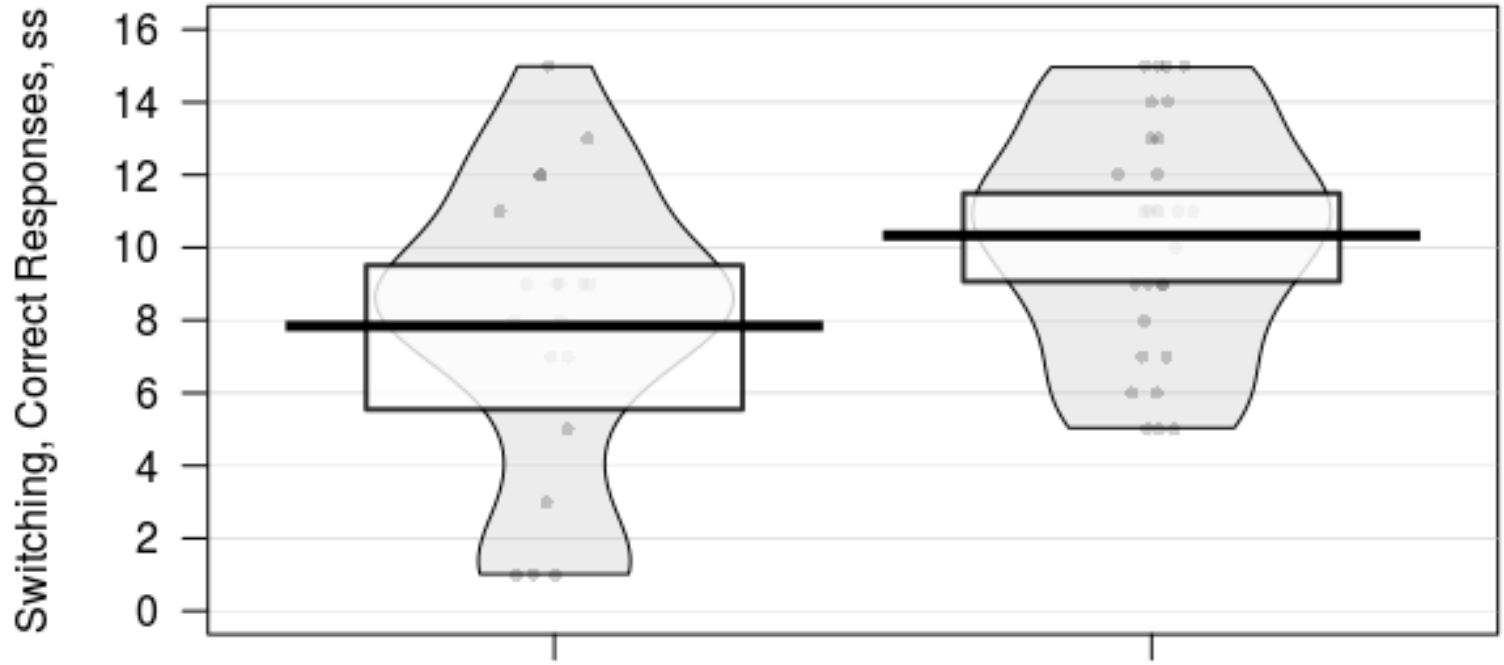

PD with $p R B D$

PD without pRBD

Figure 1. A pirate plot comparing category switching verbal fluency task performance between Parkinson's disease (PD) individuals with and without probable rapid eye movement sleep behavior disorder (pRBD). The bars represent the means of each group. The points represent raw data. The bands around each bar represent $95 \%$ confidence intervals. The beans represent the smoothed density curve of the data distribution. The PD with pRBD group tended to perform worse on the category switching task than the PD without pRBD group did.

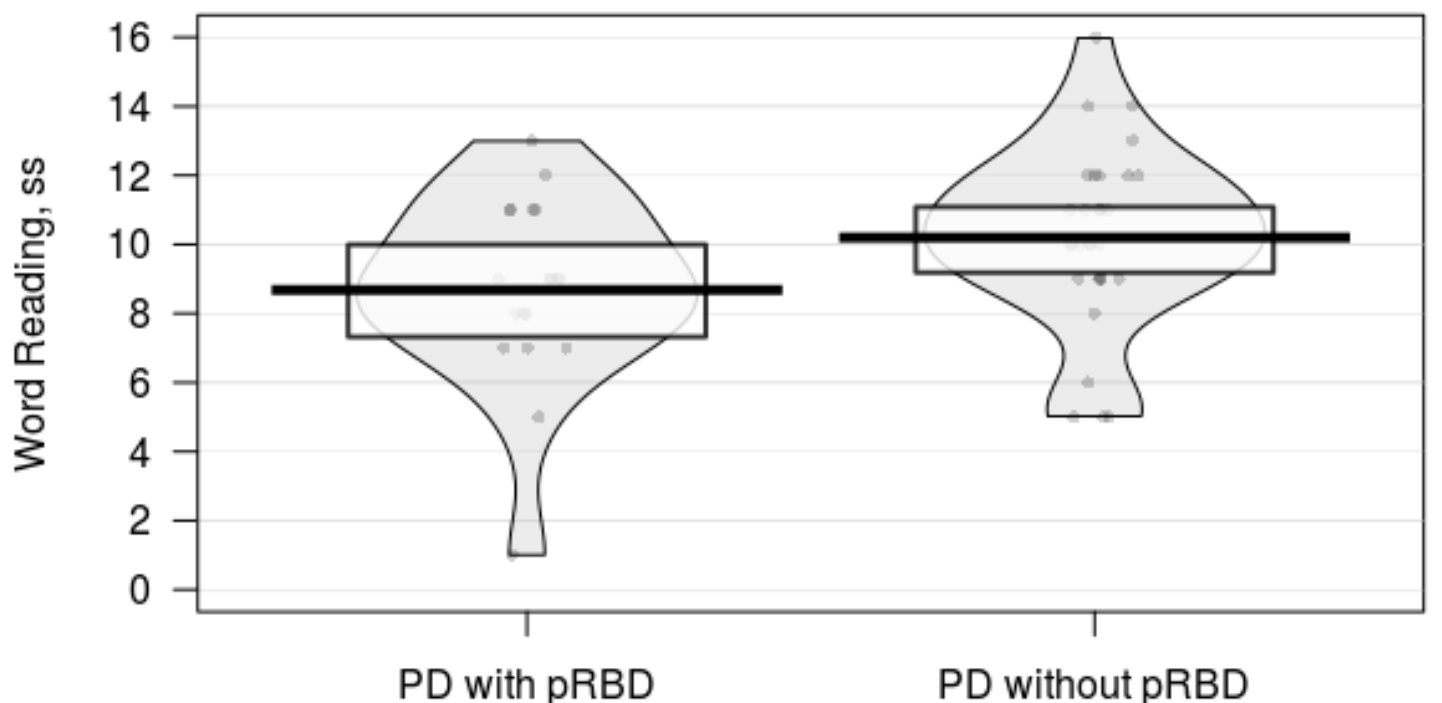

Figure 2. A pirate plot comparing word reading task performance between Parkinson's disease (PD) individuals with and without probable rapid eye movement sleep behavior disorder (pRBD). The bars represent the means of each group. The points represent raw data. The bands around each bar represent $95 \%$ confidence intervals. The beans represent the smoothed density curve of the data distribution. The PD with pRBD group tended to have a worse performance on the word reading task than the PD without pRBD group did.

\section{Discussion}

In this study, we investigated whether individuals with PD co-morbid with probable RBD had greater cognitive and sleep problems than those with PD who did not have probable RBD. We found that PD individuals with probable RBD had significant deficits in word reading and switching verbal 
fluency tasks compared to PD individuals without probable RBD. Scores on these tasks were scaled to age norms to eliminate the potential confound of age differences across groups. This cognitive finding agrees with the conclusions of previous studies that suggest an association between RBD and verbal task performance in PD individuals [18-20]. It has already been reported in some studies that PD patients demonstrate significant cognitive deficits in cognitive shifting and verbal fluency tasks [46,47], suggesting that RBD is associated with additional verbal task impairment in PD. Differing from previous studies, however, we found no significant differences between PD with or without probable RBD participants on the performance of attention, memory, and visuospatial tasks [18-20]. This discrepancy is not likely due to the advanced age of the PD and probable RBD group or the similar level of PD severity of the two groups, since other studies have included comparable sample descriptions while reporting that other cognitive domains were affected $[16,25,48]$.

We failed to detect significant differences between PD participants with or without probable RBD on self-reported sleep measures. These findings align with previous studies that suggest that PD patients with RBD do not report worse sleep problems than PD patients without RBD do [18-20,23-25]. These findings, however, conflict with previous studies that found increased daytime sleepiness and lower sleep quality in PD patients with RBD compared to those without RBD [49,50]. We note that there was a trend association suggesting that probable RBD participants may have greater sleepiness than participants without probable RBD. Again, the inability of our study to detect significant sleep differences in our group may be due to our relatively small sample size.

These results may be explained mechanistically by RBD in PD being associated with greater impairment in frontal and temporal brain circuitry, specifically with connections implicated in verbal executive functions that are unrelated to PD-specific pathology [51,52]. As neurodegeneration progresses, RBD may amplify verbal impairments found in PD, particularly those that involve switching, that already exist. In particular, since related studies have also reported verbal impairments, such as in fluency, learning, and memory tasks [18-20], these data may represent one of the most unique cognitive impairment symptoms that result from RBD in PD. Other cognitive impairments may then develop as neurodegeneration progresses in parallel or serially to regions responsible for other cognitive tasks [15].

Our findings must be considered in the context of several study limitations. The relatively small sample size of this study, particularly for the probable RBD group, and the large number of variables, limited the power of our findings. Our results may also have been confounded by the presence of comorbidities of PD that were not addressed in this study and that may have impacted the cognitive performance and sleep quality of study participants. By screening for dementia, our study may underestimate the detrimental effects of PD and RBD on cognition due to selection effects [19]. Prospective studies may provide valuable insights not possible with a cross-sectional design. Additionally, study participants were relatively young for their disease duration, which suggests that they may have a less severe PD presentation than may be found in similar studies. Because of this, these results cannot be generalized to PD individuals with a greater disease severity.

\section{Conclusions}

In recent years, studies have identified RBD as an important prodrome and comorbidity of PD. This study adds to the literature focused on understanding the detrimental effects of RBD on cognition and self-reported sleep impairment in early-stage PD patients. The results of this study suggest that RBD in early-stage PD is most strongly associated with verbal tasks involving word reading or switching verbal fluency, difficulties that exceed those seen in PD patients without RBD. These cognitive deficits may represent some of the more unique impairments associated with RBD in PD and could potentially be targeted by therapies to ameliorate these deficits.

Author Contributions: Conceptualization, D.B., J.T., T.C., M.B.B. and D.B.K.; methodology, D.B.K. and D.B.; software, C.N.S.; validation, J.T. and D.B.K.; formal analysis, J.T. and M.B.B.; investigation, N/A; resources, N/A; data curation, D.B.K., J.J.T., and D.B.; writing - original draft preparation, J.T., T.C., and D.K.; writing一review and editing, J.T., J.J.T., C.N.S., T.C., M.B.B., D.B., and D.B.K.; visualization, M.B.B., J.T., and D.B.K.; supervision, 
D.B.K. and D.B.; project administration, D.B.K.; funding acquisition, D.B.K. All authors have read and agreed to the published version of the manuscript.

Funding: Ethel Moore Alzheimer's Program, National Institutes of Health, (Grant/Award Number: T32 NS082168); National Institute on Aging, (Grant/Award Number: R01 AG054370, R21 AG057200, T32 AG020499); National Institute of Mental Health, (Grant/Award Number: R03 MH109336); National Institute of Child Health and Human Development, (Grant/Award Number: R01 HD091658); National Institute of Nursing Research, (Grant/Award Number: R01 NR014810); State of Florida Education, National Institute of Neurological Disorders and Stroke, (Grant/Award Number: R01 NS082386, R01 NS096008, UH3 NS095553).

Acknowledgments: We acknowledge Darren Black for his help in creating the pirate plots.

Conflicts of Interest: The authors declare no conflict of interest.

\section{References}

1. Dubois, B.; Pillon, B. Cognitive deficits in Parkinson's disease. J. Neurol. 1996, 244, 2-8. [CrossRef]

2. Foltynie, T.; Brayne, C.E.G.; Robbins, T.W.; Barker, R.A. The cognitive ability of an incident cohort of Parkinson's patients in the UK. The CamPaIGN study. Brain 2004, 127, 550-560. [CrossRef]

3. Galvin, J.E. Cognitive change in Parkinson Disease. Alzheimer Dis. Assoc. Disord. 2006, 20, 302-310. [CrossRef] [PubMed]

4. Weintraub, D.; Moberg, P.J.; Culbertson, W.C.; Duda, J.E.; Katz, I.R.; Stern, M.B. Dimensions of executive function in Parkinson's disease. Dement. Geriatr. Cogn. Disord. 2005, 20, 140-144. [CrossRef] [PubMed]

5. Zhang, X.; Sun, X.; Wang, J.; Tang, L.; Xie, A. Prevalence of rapid eye movement sleep behavior disorder (RBD) in Parkinson's disease: A meta and meta-regression analysis. Neurol. Sci. 2017, 38, 163-170. [CrossRef] [PubMed]

6. Aarsland, D.; Kurz, M.W. The epidemiology of dementia associated with Parkinson Disease. J. Neurol. Sci. 2010, 289, 18-22. [CrossRef] [PubMed]

7. Hely, M.A.; Reid, W.G.; Adena, M.A.; Halliday, G.M.; Morris, J.G.L. The Sydney multicenter study of Parkinson's disease: The inevitability of dementia at 20 years. Mov. Disord. 2008, 23, 837-844. [CrossRef] [PubMed]

8. Gunn, D.G.; Naismith, S.L.; Lewis, S.J. Sleep disturbances in Parkinson Disease and their potential role in heterogeneity. J. Geriatr. Psychiatry Neurol. 2010, 23, 131-137. [CrossRef] [PubMed]

9. Seugnet, L.; Galvin, J.E.; Suzuki, Y.; Gottschalk, L.; Shaw, P.J. Persistent short-term memory defects following sleep deprivation in a drosophila model of Parkinson Disease. Sleep 2009, 32, 984-992. [CrossRef]

10. Bergonzi, P.; Chiurulla, C.; Gambi, D.; Mennuni, G.; Pinto, F. L-dopa plus dopa-decarboxylase inhibitor: Sleep organization in Parkinson's syndrome before and after treatment. Acta Neurol. Belg. 1975, 75, 5-10.

11. Mitra, T.; Chaudhuri, K.R. Sleep dysfunction and role of dysautonomia in Parkinson's disease. Parkinsonism Relat. Disord. 2009, 15, S93-S95. [CrossRef]

12. Alatriste-Booth, V.; Rodriguez-Violante, M.; Camacho-Ordonez, A.; Cervantes-Arriaga, C. Prevalence and correlates of sleep disorders in Parkinson's disease: A polysomnographic study. Arq. Neuro-Psiquiatr. 2015, 73, 241-245. [CrossRef] [PubMed]

13. Gomutbutra, P.; Kanjanaratanakorn, K.; Tiyapun, N. Prevalence and clinical characteristics of Probable REM Behavior Disorder in Thai Parkinson's disease patients. Parkinson's Dis. 2018, 2018, 1-6. [CrossRef] [PubMed]

14. De Cock, V.C.; Vidailhet, M.; Leu, S.; Texeira, A.; Apartis, E.; Elbaz, A.; Roze, E.; Willer, J.C.; Derenne, J.P.; Agid, Y.; et al. Restoration of normal motor control in Parkinson's disease during REM sleep. Brain 2007, 130, 450-456. [CrossRef] [PubMed]

15. Manni, R.; Sinforiani, E.; Pacchetti, C.; Zucchella, C.; Cremascoli, R.; Terzaghi, M. Cognitive dysfunction and REM sleep behavior disorder: Key findings in the literature and preliminary longitudinal findings. Int. J. Psychophysiol. 2013, 89, 213-217. [CrossRef] [PubMed]

16. Massicotte-Marquez, J.; Decary, A.; Gagnon, J.F.; Vendette, M.; Mathieu, A.; Postuma, R.B.; Carrier, J.; Montplaisir, J. Executive dysfunction and memory impairment in idiopathic REM sleep behavior disorder. Neurology 2008, 70, 1250-1257. [CrossRef]

17. Nomura, T.; Kishi, M.; Nakashima, K. Differences in clinical characteristics when REM sleep behavior disorder precedes or comes after the onset of Parkinson's disease. J. Neurol. Sci. 2017, 382, 58-60. [CrossRef] 
18. Postuma, R.B.; Bertrand, J.-A.; Montplaisir, J.; Desjardins, C.; Vendette, M.; Rios Romenets, S.; Panisset, M.; Gagnon, J.-F. Rapid eye movement sleep behavior disorder and risk of dementia in Parkinson's disease: A prospective study. Mov. Disord. 2012, 27, 720-726. [CrossRef]

19. Chahine, L.M.; Xie, S.X.; Simuni, T.; Tran, B.; Postuma, R.; Amara, A.; Oertel, W.H.; Iranzo, A.; Scordia, C.; Fullard, M.; et al. Longitudinal changes in cognition in early Parkinson's disease patients with REM sleep behavior disorder. Parkinsonism Relat. Disord. 2016, 27, 102-106. [CrossRef]

20. Jozwiak, N.; Postuma, R.B.; Montplaisir, J.; Latreille, V.; Panisset, M.; Chouinard, S.; Bourgouin, P.-A.; Gagnon, J.-F. REM sleep behavior disorder and cognitive impairment in Parkinson's Disease. Sleep 2017, 40, 1-10. [CrossRef]

21. Kamble, N.; Yadav, R.; Lenka, A.; Kumar, K.; Nagaraju, B.C.; Pal, P.K. Impaired sleep quality and cognition in patients of Parkinson's disease with REM sleep behavior disorder: A comparative study. Sleep Med. 2019, 62, 1-5. [CrossRef] [PubMed]

22. Yan, Y.; Lei, K.; Li, Y.; Liu, X.F.; Chang, Y. The correlation between possible RBD and cognitive function in Parkinson's disease patients in China. Ann. Clin. Transl. Neurol. 2019, 6, 848-853. [CrossRef] [PubMed]

23. Gagnon, J.-F.; Vendette, M.; Postuma, R.B.; Desjardins, C.; Massicotte-Marquez, J.; Panisset, M.; Montplaisir, J. Mild cognitive impairment in rapid eye movement sleep behavior disorder and Parkinson's disease. Ann. Neurol. 2009, 66, 39-47. [CrossRef] [PubMed]

24. Vendette, M.; Gagnon, J.-F.; Decary, A.; Massicotte-Marquez, J.; Postuma, R.B.; Doyon, J.; Panisset, M.; Montplaisir, J. REM sleep behavior disorder predicts cognitive impairment in Parkinson Disease without dementia. Neurology 2007, 69, 1843-1849. [CrossRef] [PubMed]

25. Neikrug, A.B.; Maglione, J.E.; Liu, L.; Natarajan, L.; Avanzino, J.A.; Corey-Bloom, J.; Palmer, B.W.; Loredo, J.S.; Ancoli-Israel, S. Effects of sleep disorders on the non-motor symptoms of Parkinson Disease. J. Clin. Sleep Med. 2013, 9, 1119-1129. [PubMed]

26. Poryazova, R.; Oberholzer, M.; Baumann, C.R.; Bassetti, C.L. REM sleep behavior disorder in Parkinson's disease: A questionnaire-based survey. J. Clin. Sleep Med. 2013, 9, 55-59. [CrossRef]

27. Postuma, R.B.; Gagnon, J.-F.; Pelletier, A.; Montplaisir, J.Y. Insomnia and somnolence in idiopathic RBD: A prospective cohort study. NPJ Parkinson's Dis. 2017, 3, 9. [CrossRef]

28. Stiasny-Kolster, K.; Sixel-Doring, F.; Trenkwalder, C.; Heinzel-Gutenbrunner, M.; Seppi, K.; Poewe, W.; Hogl, B.; Frauscher, B. Diagnostic value of the REM sleep behavior disorder screening questionnaire in Parkinson's disease. Sleep Med. 2015, 16, 186-189. [CrossRef]

29. Kay, D.B.; Tanner, J.J.; Bowers, D. Sleep disturbances and depression severity in patients with Parkinson's disease. Brain Behav. 2018, 8, e00967. [CrossRef]

30. Fahn, S.; Elton, R.L. Recent Developments in Parkinson's Disease; Fahn, S., Marsden, C.D., Calne, D.B., Goldstein, M., Eds.; Macmillan Healthcare Information: Florham Park, NJ, USA, 1987; pp. 153-163.

31. Hoehn, M.M.; Yahr, M.D. Parkinsonism: Onset, progression and mortality. Neurology 1967, 17, 427-442. [CrossRef]

32. Kroenke, K.; Spitzer, R.L.; Williams, J.B. The PHQ-9: Validity of a brief depression severity measure. J. Gen. Intern. Med. 2001, 16, 606-613. [CrossRef] [PubMed]

33. Kukull, W.A.; Larson, E.B.; Teri, L.; Bowen, J.; McCormick, W.; Pfanschmidt, M.L. The Mini-Mental State Examination score and the clinical diagnosis of dementia. J. Clin. Epidemiol. 1994, 47, 1061-1067. [CrossRef]

34. Spielberger, C.D.; Gorsuch, R.L.; Lushene, R. STAI Manual; Consulting Psychologists Press: Palo Alto, CA, USA, 1970.

35. Delis, D.C.; Kaplan, E.; Kramer, J.H. The Delis-Kaplan Executive Function System; The Psychological Corporation: San Antonio, TX, USA, 2001.

36. Benton, A.L.; Hamsher, K.D.; Varney, N.R.; Spreen, O. Contributions to Neuropsychological Assessment: A Clinical Manual; Oxford University Press, Inc.: Oxford, NY, USA, 1983.

37. Ivnik, R.J.; Malec, J.F.; Smith, G.E.; Tangalos, E.G.; Petersen, R.C. Neuropsychological tests' norms above age 55: COWAT, BNT, MAE token, WRAT-R reading, AMNART, STROOP, TMT, and JLO. Clin. Neuropsychol. 1996, 10, 262-278. [CrossRef]

38. Kirchner, W.K. Age differences in short-term retention of rapidly changing information. J. Exp. Psychol. 1958, 55, 352-358. [CrossRef]

39. Altena, E.; van Der Werf, Y.D.; Strijers, R.L.; van Someren, E.J. Sleep loss affects vigilance: Effects of chronic insomnia and sleep therapy. J. Sleep Res. 2008, 17, 335-343. [CrossRef] 
40. Newcomer, J.W.; Selke, G.; Melson, A.K.; Hershey, T.; Craft, S.; Richards, K.; Alderson, A.L. Decreased memory performance in healthy humans induced by stress-level cortisol treatment. Arch. Gen. Psychiatry 1999, 56, 527-533. [CrossRef]

41. Buysse, D.J.; Reynolds, C.F., III; Monk, T.H.; Hoch, C.C.; Yeager, A.L.; Kupfer, D.J. Quantification of subjective sleep quality in healthy elderly men and women using the Pittsburgh Sleep Quality Index (PSQI). Sleep 1991, 14, 331-338.

42. Buysse, D.J.; Reynolds, C.F., III; Monk, T.H.; Berman, S.R.; Kupfer, D.J. The Pittsburgh Sleep Quality Index: A new instrument for psychiatric practice and research. Psychiatry Res. 1989, 28, 193-213. [CrossRef]

43. Bastien, C.H.; Vallieres, A.; Morin, C.M. Validation of the Insomnia Severity Index as an outcome measure for insomnia research. Sleep Med. 2001, 2, 297-307. [CrossRef]

44. Johns, M.W. A new method for measuring daytime sleepiness: The Epworth sleepiness scale. Sleep 1991, 14, 540-545. [CrossRef]

45. Cella, D.; Riley, W.; Stone, A.; Rothrock, N.; Reeve, B.; Yount, S.; Amtmann, D.; Bode, R.; Buysse, D.; Choi, S.; et al. The Patient-Reported Outcomes Measurement Information System (PROMIS) developed and tested its first wave of adult self-reported health outcome item banks: 2005-2008. J. Clin. Epidemiol. 2010, 63, 1179-1194. [CrossRef] [PubMed]

46. Hsieh, Y.H.; Chen, K.J.; Wang, C.C.; Lai, C.L. Cognitive and motor components of response speed in the stroop test in Parkinson's disease patients. Kaohsiung J. Med. Sci. 2008, 24, 197-203. [CrossRef]

47. Obeso, I.; Wilkinson, L.; Casabona, E.; Bringas, M.L.; Alvarez, M.; Alvarez, L.; Alvarez, L.; Pavon, N.; Rodriguez-Oroz, M.-C.; Macias, R.; et al. Deficits in inhibitory control and conflict resolution on cognitive and motor tasks in Parkinson's disease. Exp. Brain Res. 2011, 212, 371-384. [CrossRef]

48. Sinforiani, E.; Zangaglia, R.; Manni, R.; Cristina, S.; Marchioni, E.; Nappi, G.; Mancini, F.; Pacchetti, C. REM Sleep Behavior Disorder, hallucinations, and cognitive impairment in Parkinson's Disease. Mov. Disord. 2006, 21, 462-466. [CrossRef] [PubMed]

49. Arnulf, I.; Neutel, D.; Herlin, B.; Golmard, J.L.; Leu-Semenescu, S.; Cochen de Cock, V.; Vidailhet, M. Sleepiness in idiopathic REM sleep behavior disorder and Parkinson Disease. Sleep 2015, 38, 1529-1535. [CrossRef]

50. Mahale, R.; Yadav, R.; Pal, P.K. Rapid eye movement sleep behaviour disorder in young- and older-onset Parkinson Disease: A questionnaire-based study. Sleep Med. 2014, 15, 642-646. [CrossRef] [PubMed]

51. Henry, J.D.; Crawford, J.R. A Meta-Analytic Review of verbal fluency performance in patients with traumatic brain injury. Neuropsychology 2004, 18, 621-628. [CrossRef]

52. El-Nazer, R.; Adler, C.H.; Beach, T.G.; Belden, C.M.; Artz, J.; Shill, H.A.; Driver-Dunckley, E.; Mehta, S.H.; Sabbagh, M.N.; Serrano, G.E.; et al. Regional neuropathology distribution and verbal fluency impairments in Parkinson's Disease. Park Rel. Dis. 2019, 65, 73-78. [CrossRef]

(C) 2019 by the authors. Licensee MDPI, Basel, Switzerland. This article is an open access article distributed under the terms and conditions of the Creative Commons Attribution (CC BY) license (http://creativecommons.org/licenses/by/4.0/). 